\title{
MANAJEMEN REPRODUKSI DAN PAKAN UNTUK MENINGKATKAN PERFORMANS TERNAK DI DESA TUGU REJO-KABAWETAN, KEPAHIANG BENGKULU
}

\section{(REPRODUCTIVE AND FEEDING MANAGEMENT TO IMPROVE THE PERFORMANCE OF LIVESTOCK IN TUGU REJO, KABAWETAN DISTRICT KEPAHIANG BENGKULU)}

\author{
Oleh: \\ Dwatmadji, Tatik Suteky, Edi Sutrisno \\ Jurusan Peternakan Fakultas Pertanian Universitas Bengkulu \\ Dwatmadji.2008@gmail.com
}

\begin{abstract}
The population of cattle and goats, in Tugu Rejo village, is poorly developed, characterized by lower calf cow production, prolonged calving/kidding interval. The main problem identified from Tugu Rejo Village is the lack of knowledge of farmers on breeding and feed management. The purpose of this activity was to improve farmer knowledge about reproductive and feeding management through an extension and guidance to the farmers. The results of the activity can increase knowledge breeding management, about prevention of distocia, arrangement of cross breeding, prevention of inbreeding for goats. To improve the efficiency of breeding, breeders should be able to utilize breeding diagrams to regulate the mating system in livestock and feeding management during lactation.
\end{abstract}

Keyword: management, reproductive, feed, livestock

\section{PENDAHULUAN}

Performans reproduksi ternak sangat berkaitan dengan manajemen reproduksi dan pakan. Manajemen reproduksi merupakan salah satu aspek utama untuk keberlangsungan hidup usaha peternakan (Suharyati dan Hartono, 2015). Efisiensi reproduksi ternak dapat dicapai apabila manajemen reproduksinya baik (Hardjopranjoto, 1995 dan Partodihardjo, 1985). Gangguan reproduksi ditandai dengan rendahnya fertilitas induk, conception rate, dan calvng/kidding rate yang dapat mengakibatkan penurunan populasi ternak dan pasokan penyediaan daging secara nasional. Bagi peternak gangguan reproduksi pada ternak dapat menimbulkan kerugian ekonomi. Banyak faktor mempengaruhi performans reproduksi ternak antara lain (1) pola perkawinan yang kurang benar, (2) rendahnya pengetahuan peternak tentang deteksi birahi, (3) rendahnya kualitas atau kurang tepatnya pemanfaatan pejantan dalam kawin alam (4) kurang terampilnya inseminator (5) kurang tepatnya pelaksanaan IB (6), rendahnya pengetahuan peternak tentang manajemen reproduksi, (7) gangguan reproduksi, dan (8) lingkungan termasuk manajemen pakan.

Memahami keterkaitan berbagai faktor yang mempengaruhi fertilitas ternak, merupakan hal yang esensial dalam upaya mengoptimalkan performans reproduksi. 
Populasi ternak ruminansia, terutama sapi dan kambing, di Desa Tugu Rejo, kurang berkembang dengan baik, jarak kelahiran yang relatif panjang yakni sekitar 10 bulan, dan produktivitas rendah. Persoalan utama yang teridentifikasi dari Desa Tugu Rejo adalah rendahnya produktivitas ternak ruminansia disebabkan kurangnya pengetahuan petani ternak tentang manajemen breeding dan pakan.

Oleh karena itu peternak harus mampu mengetahui tata kelola manajemen reproduksi antara lain pola perkawinan, manajemen pakan, deteksi dan gejala estrus termasuk gangguan reproduksi. Kurang lebih 95\% efisiensi reproduksi ditentukan oleh faktor-faktor non genetis, hal ini artinya kegagalan reproduksi banyak dipengaruhi oleh lingkungan dan manajemen. Hasil penelitian Suharyati dan Hartono (2016) menunjukkan bahwa pengetahuan peternak terkait reproduksi akan mengurangi kejadian repeat breeding. Iswoyo dan Widiyaningrum (2008) menyatakan bahwa performa reproduksi sapi peranakan Simental yang dipelihara peternak anggota kelompok tani ternak (KTT) secara umum lebih baik dibanding sapi peranakan Simental yang dipelihara peternak non KTT. Manajemen perkawinan ternak yang tidak sesuai dengan kondisi lingkungan, potensi, kehendak petani kehidupan sosial masyarakat pedesaan bisa menyebabkan rendahnya angka kebuntingan dan panjangnya calving/kidding interval. Kegiatan penyuluhan dan pelatihan ini dilakukan untuk meningkatkan pengetahuan kelompok tani ternak Sidodadi 2 berdasarkan potensi dan sumber daya masyarakat sasaran, kondisi dan lingkungan ternak.

\section{METODE PENGABDIAN}

Sasaran kegiatan IbM adalah kelompok tani ternak Sidodadi 2, Kecamatan Kabawetan Kabupaten Kepahiang. Dosen yang terlibat sebanyak 3 orang (tim pelaksana) 3 mahasiswa Jurusan Peternakan dan 2 orang alumni Jurusan Peternakan yang berprofesi sebagai peternak sapi perah di Desa Tangsi Duren. Peranan mahasiswa sebagai pembantu pelaksanaan kegiatan. Karena penyuluhan merupakan metode yang efektif untuk penyampaian ilmu pengetahuan ke kalayak sasaran maka dalam kegiatan IbM ini penyuluhan dilakukan untuk menyampaikan materi. Penyuluhan manajemen reproduksi dilaksanakan pada tanggal 28 Agustus 2016, sedangkan pelatihan membaca diagram breeding, kunjungan lapangan dan pendampingan dilaksanakan pada tanggal 7 September 2016. Pada tanggal 10 Oktober 2016 dilaksanakan penyuluhan tentang manajemen pakan dan meninjau potensi sumber pakan.

Tahapan pelaksanaan:

1. Tahap persiapan berupa koordinasi tim pelaksana kegiatan IbM, koordinasi dengan pengurus kelompok ternak Sidodadi 2, dan aparat desa tentang rencana kegiatan dan peserta yang akan diikutsertakan dalam kegiatan pengabdian masyarakat dilakukan sebelum penyuluhan.

2. Persiapan pengadaan bahan-bahan serta peralatan yang diperlukan.

3. Penyuluhan manajemen reproduksi dan pelatihan membaca diagram breeding 
4. Kunjungan lapangan untuk melihat kondisi ternak, untuk melatih ternak melihat performa berdasar body condition score

5. Penyuluhan tentang manajemen pakan, termasuk menggali potensi pakan yang ada di lokasi kegiatan

\section{HASIL DAN PEMBAHASAN}

Materi penyuluhan manajemen reproduksi meliputi penilaian body condition score ternak, tanda-tanda estrus, pola perkawinan ternak dan lain sebagainya. Menurut Prihatno (2006) mengenali ternak yang sedang estrus merupakan salah satu faktor penting dalam manajemen reproduksi ternak. Kegagalan dalam deteksi estrus sering ditemukan pada ternak yang mengalami estrus pendek/sub-estrus atau birahi tenang/silent heat, atau bisa juga disebabkan peternaknya belum berpengalaman. Lama estrus tergantung juga dengan lingkungan tempat ternak di pelihara (Akma et al., 2016). Peternak yang sudah berpengalaman mampu mendeteksi birahi dari perubahan tingkah laku ternak atau perubahan pada organ reproduksi luar nya. Deteksi birahi harus dilakukan 2 kali yakni pada pagi dan sore hari, menurut Laming (2004) 60\% ternak sapi menunjukkan gejala estrus pada pagi hari sedang $40 \%$ pada sore hari.

Dalam diskusi pada kegiatan penyuluhan terungkap bahwa beberapa peternak pernah mempunyai problem antara lain:

1. Cross breeding antara sapi Bali betina dengan sapi mengakibatkan kematian pedet. Upaya masyarakat untuk melakukan cross breeding pantas diberi apresiasi karena ukuran (bobot) sapi yang dihasilkan lebih besar, sehingga harga jual pedet untuk sapi bakalan jauh lebih tinggi dibandingkan dengan sapi lokal.

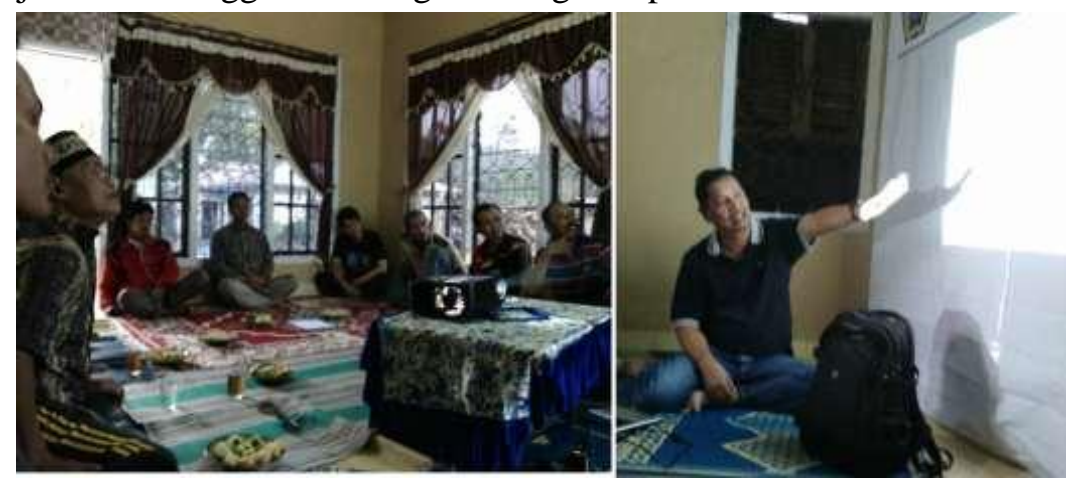

Gambar 1. Kegiatan penyuluhan

Menurut Diwyanto dan Inounu (2009), keuntungan cross breeding adalah untuk memperbaiki fitness dan viability (daya hidup) atau untuk menghasilkan sapi dengan kombinasi genetik sifat-sifat keunggulan dari dua tetuanya. Permasalahannya adalah cross breeding pada kondisi yang tidak tepat akan mengakibatkan kematian fetus/pedet, solusi dari permasalahan ini adalah sapi Bali bisa di kawinkan dengan Simental atau ternak dari bangsa Bos Taurus lainnya apabila status nya multipara setidaknya sudah pada para ke-4. Peternak sapi disarankan agar memiliki catatan (recording) untuk masing-masing 
ternaknya yang mencakup nama pejantan untuk IB, tanggal IB dan lain-lain.

2. Estrus post partum (EPP) sapi cross breeding di kelompok tani Sidodadi 2 sekitar 6 bulan, estrus post partum yang normal 1-3 bulan (Christoffor dan Baliarti, 2008; Toelihere, 1981, Akma et al., 2016, Hafez, 2000; Iswoyo dan Widiyaningrum, 2008; Nuryadi dan Wahjuningsih, 2011). Lamanya EPP tergantung manajemen dan lingkungan (Akma et al., 2016) bangsa ternak, mundurnya EPP bisa disebabkan karena penyapihan anak sangat terlambat, sehingga induk mengalami days open sangat lama yang selanjutnya berdampak pada jarak beranak (Diwyanto dan. Inounu, 2009), kasus EPP yang lama di kelompok tani ternak Sidorejo 2 bisa juga berkaitan dengan adanya kasus distokia sehingga proses involusi uterus menjadi lama. Prentice (2006) mengemukakan bahwa Voluntary Waiting Period memberi kesempatan berlangsungnya involusi uterus atau pemulihan kondisi organ reproduksi induk setelah melahirkan hingga induk siap kembali untuk proses reproduksi selanjutnya. Lebih lanjut Prentice (2006) mengambarkan hubungan antara lamanya VWP dengan kerugian ekonomi pada sapi perah.

3.

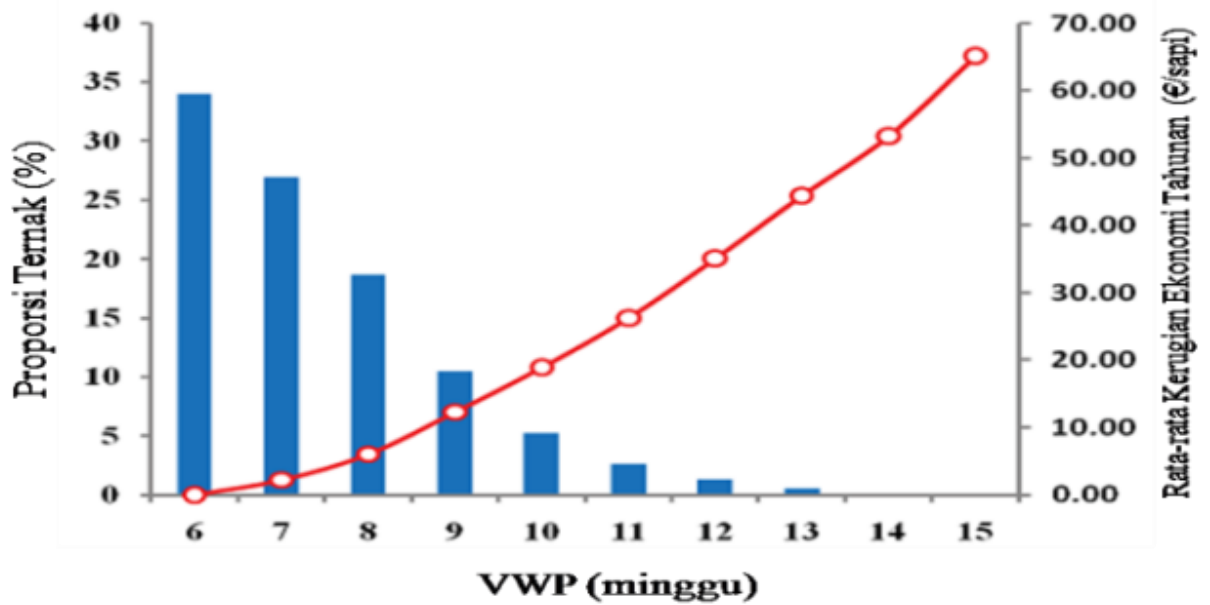

Gambar 2. Pengaruh lama Voluntary Waiting Periode (VWP) dengan rata-rata kerugian ekonomi tahunan pada sapi perah (Prentice 2006).

4. Permasalahan yang berikut adalah banyaknya kasus in breeding terutama pada pada kambing. Sharing pejantan dengan peternak yang lainnya, merupakan metode/cara yang paling memungkinakan untuk menghindari perkawinan sekeluarga. Peternak juga dilatih untuk melakukan seleksi bibit, ternak yang memiliki produktivitas unggul harus dipelihara sedang ternak yang produktivitas rendah atau mothering ability tidak bagus harus di afkir. Peternak disarankan memiliki catatan (recording), hasil penelitian Mulyawati et al. (2016) menunjukkan peternak yang memiliki pencatatan dapat melakukan evaluasi dalam usaha pemeliharaan kambing dan dapat digunakan untuk penilaian perkembangan usaha serta pengambilan keputusan untuk kelanjutan usahanya. 

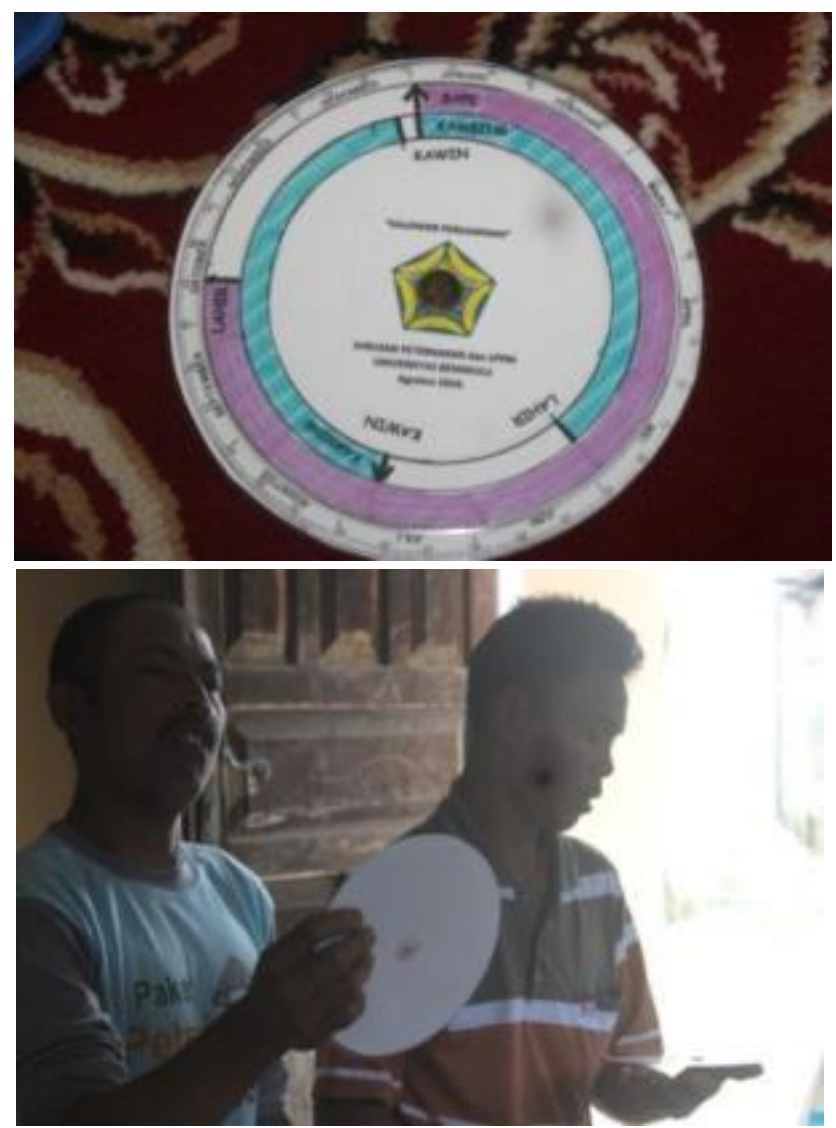

Gambar 3. Pelatihan membaca diagram breeding

Pelatihan tentang aplikasi kalender breeding/diagram breeding ditujukan untuk memudahkan peternak mengawinkan ternaknya ketika estrus atau estrus kembali pasca melahirkan (estrus post partum) agar reproduksi menjadi efisien, karena peternak tidak perlu mengingat-ingat tetapi cukup dengan melihat catatan atau diagram breeding-nya. Diagram breeding atau kalender breeding berisi simulasi tanggal ternak kawin, perkiraan melahirkan, waktu sapih, kawin setelah beranak. Dalam pelatihan juga diajarkan program pemberian pakan (surge feeding) untuk ternak pada saat pre puber, saat perkawinan, dan saat menyusui/pasca beranak.

Hasil evaluasi tentang pakan menunjukkan bahwa sebagian besar petani ternak memberi pakan ke ternak dengan berbagai jenis Hijauan Pakan Ternak (HPT) yang berupa rumput jenis unggul, antara lain rumput gajah, kolonjono, mexico, dan setaria. Jenis rumput unggul tersebut sengaja ditanam oleh petani ternak di lahan miliknya, baik di kebun, galengan sawah, dan jalan-jalan menuju kebun kopi miliknya. Pemanenan HPT di lapangan selanjutnya dibawa baik dengan gerobak, motor ataupun mobil ke kandang masing-masing untuk diberikan ke ternaknya, seperti nampak dalam Gambar 4. 

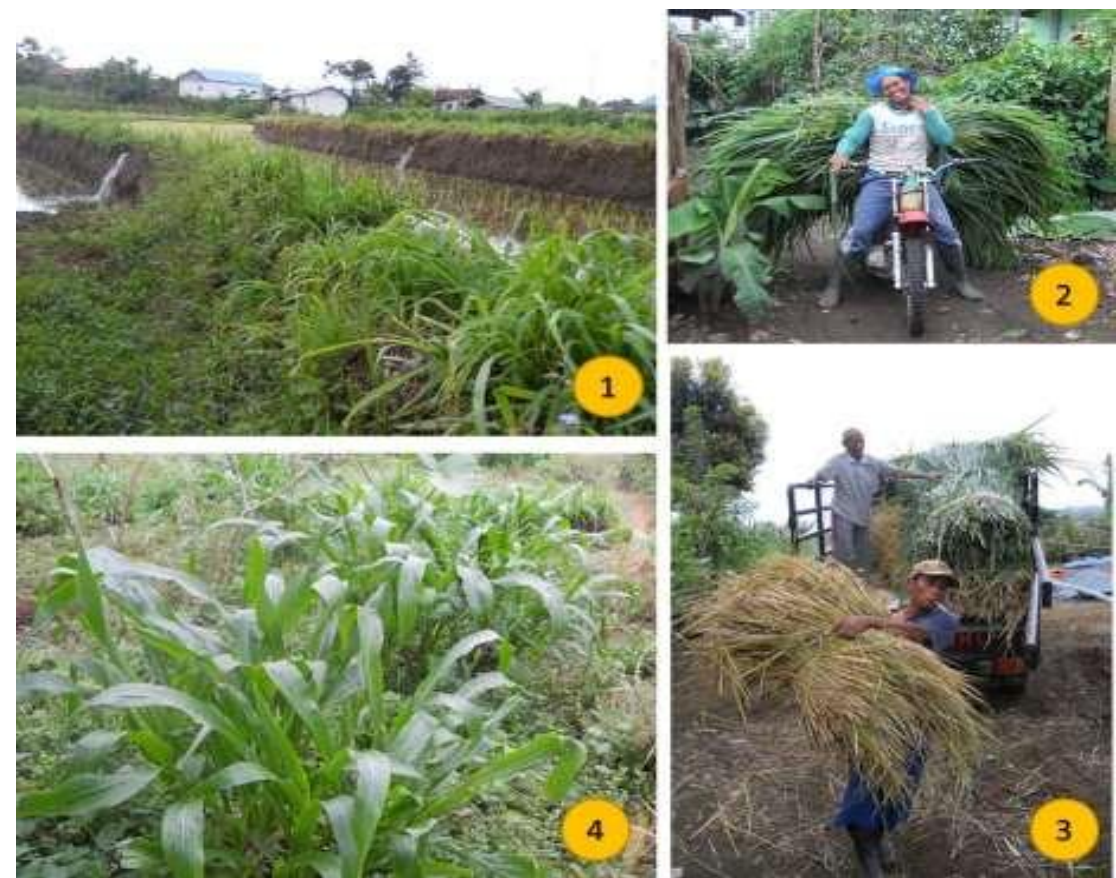

Gambar 4. Jenis rumput unggul yang ditanam di galengan sawah (1) dan di pinggir jalan (4) dan dibawa dengan motor (2) ataupun mobil (3) menuju kandang ternak milik anggota kelompok tani Sidodadi 2, Desa Tugu rejo, Kec. Kabawetan

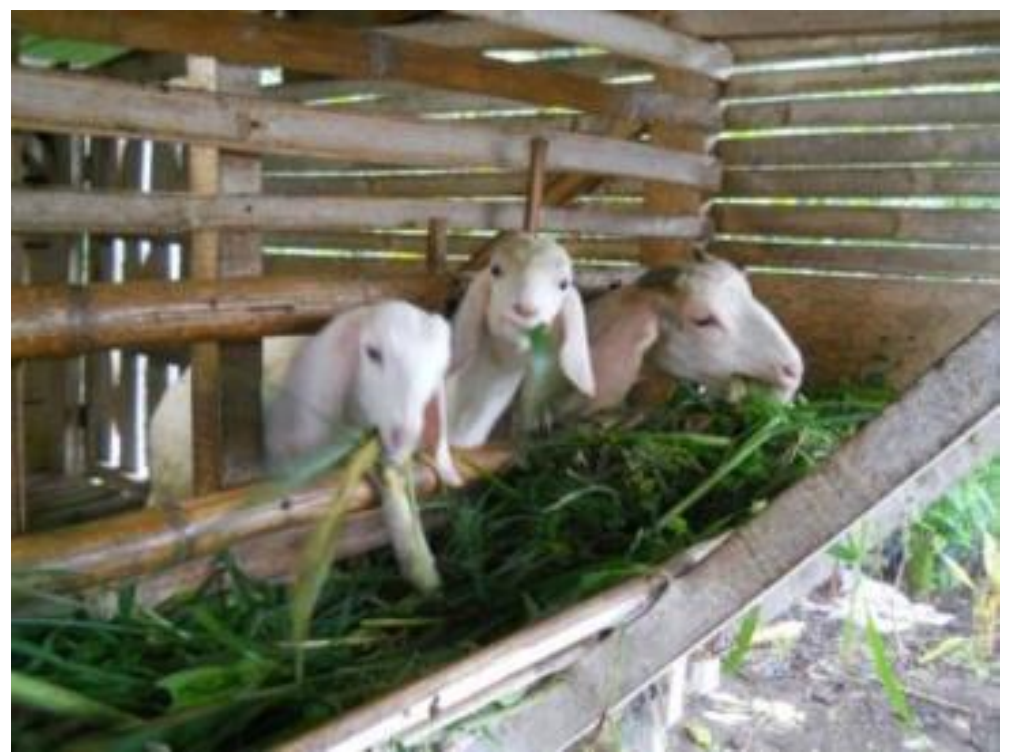

Gambar 5. Kambing yang dikandangkan kelompok tani Sidodadi 


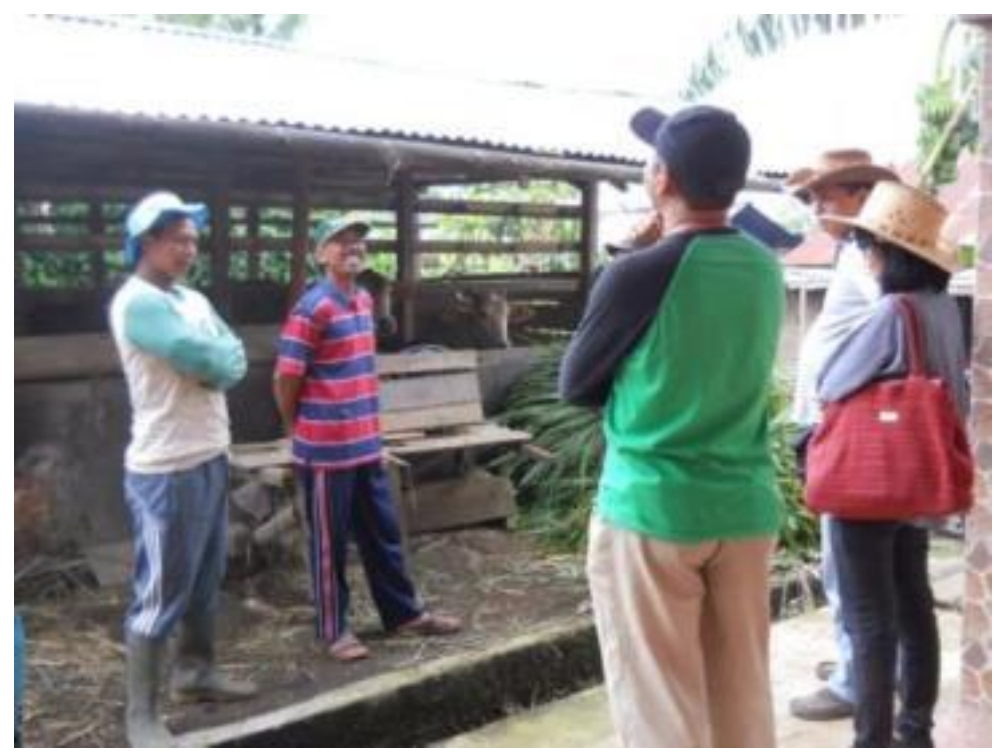

Gambar 5. Kunjungan lapangan untuk melihat kondisi ternak kambing dan sapi

Sejauh ini petani ternak Desa Tugu Rejo belum memperhatikan kapan rumput harus dipanen, pada hal umur pemanenan merupakan hal yang sangat penting karena akan sangat berkaitan dengan kualitas nutrisi.

\section{KESIMPULAN DAN SARAN}

Kegiatan penyuluhan dan pelatihan manajemen reproduksi dan pakan mampu meningkatkan pengetahuan dan wawasan peternak. Cross breeding pada sapi bisa dilakukan apabila kondisi betina lokal sudah melahirkan ke-4, untuk meningkatkan performans reproduksi kambing peternak harus sharin pejantan dengan peternak lain agar tidak terjadi inbreeding. Peternak harus bisa memanfaatkan diagram breeding dan manajemen pakan yang baik untuk meningkatkan efisiensi reproduksi.

\section{UCAPAN TERIMA KASIH}

Kegiatan pengabdian pada masyarakat ini didanai oleh DP2M Kemenristek Dikti dengan nomer kontrak No 918/UN30.15/PM/2016.

\section{DAFTAR PUSTAKA}

Akma G.S., L.W. Pribadi and M. Yassin, 2016, Reproductive Performance of Indigenous Bali Cows in the Different Farming Management and Thermal Environment of Lombok Island Indonesia, Journal of Agriculture and Veterinary Science, 9 (12): 8389.

Christoffor W.T.H.M., dan E. Baliarti, 2008, Kinerja Reproduksi Induk Sapi Silangan Simmental Peranakan Ongole dan Sapi Peranakan Ongole Periode Postpartum, 
Sains Peternakan, 6 (2): 45-55.

Diwyanto K., dan I. Inounu, 2009, Dampak Crossbreeding dalam Program Inseminasi

Buatan terhadap Kinerja Reproduksi dan Budidaya Sapi Potong, Wartazoa 19 (2):

93-102.

Hardjopranjoto, 1995, Ilmu Kemajiran pada Ternak, Airlangga University Press, hal 103$114,139-146$.

Iswoyo dan P. Widiyaningrum, 2008, Performans Reproduksi Sapi Peranakan Simmental

(Psm) Hasil Inseminasi Buatan di Kabupaten Sukoharjo Jawa Tengah, Jurnal ilmiah

Ilmu-Ilmu Peternakan, 11 (3): 125-133.

Laming, S., 2004, Performans Reproduksi Sapi Perah dan Sahiwal Cross di Kabupaten Enrekang, Skripsi, Fakultas Peternakan Universitas Hasanuddin, Makassar.

Mulyawati I.M., D. Mardiningsih, S. Satmoko, 2016, Pengaruh Umur, Pendidikan,

Pengalaman dan Jumlah Ternak Peternak Kambing terhadap Perilaku Sapta Usaha

Beternak Kambing di Desa Wonosari Kecamatan Patebon, Agromedia 34 (1): 85-90

Nuryadi dan S. Wahjuningsih. 2011, Penampilan Reproduksi Sapi Peranakan Ongole Dan

Peranakan Limousin Di Kabupaten Malang, Jurnal ternak Tropika, 12 (1): 76-81.

Partodihardjo, S., 1985, Ilmu Produksi Hewan, Produksi Mutiara, Jakarta.

Prentice, D. 2006. The Voluntary Waiting Period. Abs Techical Service Condsultan.

http://animal science- extencion. tamu. edu /dairy /wdn. html /www. absglobal.com.

Prihatno, A., 2006, Beternak Sapi Perah Secara Intensif, PT. Agromedia Pustaka, Jakarta.

Suharyati S., dan M. Hartono, 2016, Pengaruh Manajemen Peternak Terhadap Efesiensi

Reproduksi Sapi Bali Di Kabupaten Pringsewu Provinsi Lampung. Jurnal Penelitian

Pertanian Terapan 16 (1): 61-67 